\title{
Tumor-Associated Antigens in Breast Cancer
}

\author{
Carmen Criscitiello \\ European Institute of Oncology, Milan, Italy
}

\section{Keywords}

Breast cancer - Tumor antigen - Vaccine

\section{Summary}

The targets for the immune system are antigens present on cancer cells; however, many are not cancer-specific and may also be found on normal tissues. These antigens are often products of mutated cellular genes, aberrantly expressed normal genes, or genes encoding viral proteins. Vaccines constitute an active and specific immunotherapy designed to stimulate the intrinsic antitumor immune response by presenting tumor-associated antigens expressed on normal tissues that are overexpressed on tumor cells.

\section{Introduction}

A basic principle of tumor immunology in general and of cancer immunosurveillance in particular is that cancer cells express antigens that differentiate them from their non-transformed counterparts. The targets for the immune system are antigens present on cancer cells; however, many are not cancer-specific and may also be found on normal tissues. These antigens are often products of mutated cellular genes, aberrantly expressed normal genes, or genes encoding viral proteins. The human tumor-associated antigens (TAAs) include differentiation antigens (such as melanocyte differentiation antigens), mutational antigens (such as p53), overexpressed cellular antigens (such as HER2), viral antigens (such as human papillomavirus proteins), and cancer/testis (CT) antigens that are expressed in germ cells of the testis and ovary but are silent in normal somatic cells (such as MAGE and NY-ESO-1).

Vaccines constitute an active and specific immunotherapy designed to stimulate the intrinsic antitumor immune response by presenting TAAs expressed on normal tissues that are overexpressed on tumor cells [1-3]. Malignant cells can

\section{KARGER}

Fax +497614520714

Information@Karger.de

www.karger.com

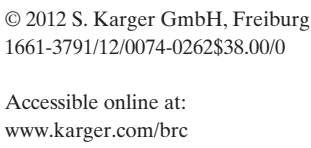

\author{
Schlüsselwörter \\ Mammakarzinom · Tumorantigen · Impfstoff
}

\section{Zusammenfassung}

Die auf Tumorzellen vorhandenen Antigene sind die Angriffspunkte für das Immunsystem. Viele dieser Antigene sind jedoch nicht tumorspezifisch und können auch auf normalen Geweben gefunden werden. Diese Antigene sind oftmals die Produkte mutierter zellulärer Gene, aberrant exprimierter normaler Gene oder virale Proteine kodierender Gene. Impfstoffe stellen eine aktive und spezifische Immuntherapie dar, deren Aufgabe es ist, eine spezifische Antitumor-Immunantwort zu stimulieren, indem sie tumorassoziierte Antigene, die auf normalen Geweben exprimiert und auf Tumorzellen überexprimiert werden, präsentieren.

express both normal self-antigens (expressed at normal or abnormal levels) and specific TAAs that arise from genetic mutations and/or epigenetic changes. These TAAs can show changes recognized by the immune response either through their loss or de novo aberrant expression. Many TAAs have been identified and shown to be specifically recognized by $\mathrm{T}$ cells [4-8]. Many tumor antigens used in breast cancer immunotherapy are expressed on normal tissues but are overexpressed or mutated on tumor cells. Some of these antigens are universal tumor antigens, as they are broadly expressed by most tumors. The ideal TAA should fulfill certain criteria [9], the major one being therapeutic function defined as a vaccineinduced clinical response within a controlled trial. The second dominant criterion is immunogenicity, i.e. the ability to elicit T-cell and/or antibody responses. Also, the antigen should be oncogenic, specific, and highly expressed on all cancer cells in patients designated for treatment. Other minor criteria are stem cell expression, number of patients with antigen-positive cancers, number of antigenic epitopes, and cellular location of antigen expression [9]. We will discuss all potential antigens that have been used to construct vaccines for the treatment of breast cancer. 


\section{Human Epidermal Growth Factor Receptor 2}

The human epidermal growth factor receptor 2 (HER2) is a $185-\mathrm{kDa}$ protein receptor with tyrosine kinase activity and extensive homology to the epidermal growth factor receptor. HER2 is expressed in many epithelial tumors and overexpressed in approximately $25 \%$ of all primary breast carcinomas. Overexpression of HER2 is associated with poor prognosis. HER2 is a suitable target because it involves an extracellular domain (ECD) that can be targeted by antibodies produced by $\mathrm{B}$ cells. These antibodies could act either via a functional pathway (i.e. blocking of the HER2 signaling pathway) or an immune mechanism such as antibody-dependent cell-mediated cytotoxicity. Spontaneous T and B cell responses have been observed in patients with HER2-positive tumors, confirming the immunogenicity of HER2 [10]. The use of HER2 peptides as a potential target for breast cancer immunotherapy arose from experimental evidence in the rat showing that immunization with a mixture of peptides derived from the ECD and intracellular domain (ICD) of human HER2, but not the whole protein, elicited a delayed hypersensitivity [11]. Based on these findings, clinical trials with HER2 peptides were conducted. These studies were associated with minimal toxicity, suggesting that it is possible to generate anti-HER2 responses also in humans without major signs of autoimmunity. Vaccination with HLA class I peptides likely requires additional antigen-specific or non-specific helper activity to generate long-lived immunity [12]. A major goal of these studies was to overcome the problems associated with using class I epitopes alone, i.e. antigen instability or aggregation because of the short length of the peptide. Interestingly, in a first study in the adjuvant setting, 29 patients with no evidence of disease after surgery for HER2-positive breast or ovarian cancer received 3 level doses of a HER2 ICD protein vaccine. The vaccine was administered intradermally, monthly for 6 months, with granulocyte-macrophage colonystimulating factor as an adjuvant. The vaccine was well tolerated. The majority of patients developed HER2 ICD-specific T-cell immunity. The dose of vaccine did not predict the magnitude of the T-cell response. The majority of patients also developed HER2-specific immunoglobulin G antibody immunity. Vaccine dose did not predict magnitude or avidity of the HER2-specific humoral immune response. Although the dose of vaccine did not impact the magnitude of T-cell or antibody immunity elicited, patients receiving the highest dose developed HER2-specific immunity more rapidly than those who received the lowest dose [13]. Another study in the adjuvant setting used a vaccine formulation containing a truncated recombinant HER2 protein (dHER2) combined with a new potent immunological adjuvant. dHER2 includes the ECD and a part of the ICD of the HER2 protein. The trial's objective was to evaluate safety and immunogenicity. The vaccine was well tolerated overall and showed minimal toxicity. No symptomatic cardiac dysfunction was observed. Antibody responses against dHER2, ICD, and ECD were elicited. Antibodies to the ECD and the ICD are induced in a dose-dependent manner, suggesting that the higher-dose vaccine may be required for future phase II and III studies. These studies suggest that in order to have a maximal induction of the immune response against HER2 in terms of antibody and T-cell responses, both the ECD and ICD of the protein should be included in the vaccine formulation. This should guarantee also the induction of a long-lasting immunological memory.

\section{Mucin 1}

Mucin 1 (MUC-1) is a membrane-associated glycoprotein expressed by many types of ductal epithelia, including pancreas, breast, lung, and gastrointestinal tract. It is overexpressed and aberrantly glycosylated in malignant cells. It is a multifunctional protein involved in the protection of mucous membranes, signal transduction, and modulation of the immune system. More than $70 \%$ of cancers overexpress MUC-1, making this antigen a potential target for immunotherapy [14]. MUC-1 is sufficiently immunogenic to elicit strong antitumor immunity as a TAA [15]. Preclinical studies using tumor cells expressing MUC-1 protein or peptide antigen concluded that MUC-1 could induce humoral response without inducing cellular response [16-19]. It seems complex generating cytotoxic T lymphocytes (CTL) effectors in vivo maybe because of the induction of T-cell anergy by tumorderived MUC-1 [20]. In the attempt to optimize MUC-1 presentation by antigen-presenting cells (APCs), several experimental studies in xenografts have targeted the mannose receptor on APCs by using antigens that have been linked to mannose [21-23]. The MUC-1 peptide-based vaccines have been able to elicit a humoral response but not a cell-mediated response [24]. These studies suggest that it is possible to elicit a CTL response against MUC-1 antigen, but the antibody response is unpredictable. Moreover, it is important to emphasize that the MUC-1 peptides used for vaccination do not resemble the form of antigen found on tumor cells. These cells in fact bear a molecule that is often underglycosylated as compared to their normal counterparts and could not be detected by antibodies elicited towards a non-glycosylated peptide.

\section{Carcinoembryonic Antigen}

Carcinoembryonic antigen (CEA) is a $180-\mathrm{kDa}$ glycoprotein that is overexpressed in a wide range of carcinomas, including colorectal, gastric, pancreatic, non-small cell lung, and breast carcinomas. It is an adhesion molecule, and its overexpression in cancer cells promotes adhesion and metastasis. CEA is one of several oncofetal antigens that may serve as a target for active anticancer-specific immunotherapy. However, as CEA 
is normally expressed, the immune system commonly becomes tolerant to it. Therefore CEA peptide-based vaccines firstly must break this tolerance. Clinical trials using a CEAbased vaccines for the treatment of different types of human cancers showed overall safety and efficacy [25-29]. Among the different CEA-based cancer vaccines, dendritic cell (DC)and recombinant viruse-based vaccines seem the most valid $[25,26]$. However, although vaccination improved time to progression (TTP) and, sometimes, survival by inducing a strong immune response, it failed to eradicate the disease maybe because of the negative effect of the tumor microenvironment on the immune response. Hence, in order to develop more efficient and effective cancer vaccines, new clinical trials combining them with chemotherapy, radiotherapy, and drugs targeting those factors responsible for immunosuppression are warranted.

\section{Human Telomerase Reverse Transcriptase}

As a potential molecular therapeutic target for cancer, the human telomerase reverse transcriptase (hTERT) has been extensively evaluated because of its wide expression in human cancer cells and critical functional role in tumor growth and development. One proposed clinical strategy is hTERTdirected immunotherapy, supported by the identification of immunogenic hTERT epitopes that triggered tumorlytic $\mathrm{T}$ cells in preclinical studies [30]. Telomerase maintains chromosomal integrity by protecting telomeric DNA that would otherwise be lost during successive rounds of cell division in rapidly dividing cells such as tumor cells. hTERT is a common and immunogenic tumor antigen expressed in about $85 \%$ of all cancers. hTERT peptides or DC-based vaccines elicit an immune response in various tumors [30,31]. A phase I clinical trial was performed to evaluate the clinical and immunological impact of vaccinating advanced cancer patients with the HLA-A2-restricted hTERT I540 peptide presented with keyhole limpet hemocyanin (KLH) by ex vivo generated autologous DCs. As measured by peptide/MHC tetramer, enzyme-linked immunospot, and cytotoxicity assays, hTERTspecific $\mathrm{T}$ lymphocytes were induced in 4 out of 7 patients with advanced breast or prostate carcinoma after vaccination with DCs pulsed with hTERT peptide. Tetramer-guided highspeed sorting and polyclonal expansion achieved highly enriched populations of hTERT-specific cells that killed tumor cells in a MHC-restricted way. Despite concerns of telomerase activity in rare normal cells, no significant toxicity was observed. Partial tumor regression in 1 patient was associated with the induction of CD8+ tumor-infiltrating lymphocytes. These results demonstrate the immunological feasibility of vaccinating patients against telomerase, and provide the rationale for targeting self-antigens with critical roles in oncogenesis [32].

\section{Sialyl-Tn}

The Tn, TF, and sialyl-Tn (STn) antigens represent the immature glycosylation products of serine and threonine of the protein core and are naturally masked by the complete glycosylate chain. All 3 epitopes are strongly expressed on cancer cells, and may be associated with disease progression and metastasis. STn is a core-region carbohydrate antigen constituted by the premature 2-6 sialylation of N-acetylgalactosamine, whose expression has been associated with some human tumors. In a randomized phase II trial, 23 patients with metastatic breast cancer were randomized to receive $100 \mathrm{mg}$ STn linked to KLH with DETOX-B adjuvant with or without low-dose cyclophosphamide (intravenous or oral). All patients developed IgG and IgM responses to STn. 2 patients reported a minor response, while 5 patients experienced stable disease. Patients pretreated with cyclophosphamide had a higher antibody titer and longer survival [33, 34]. Out of 40 patients, 33 with high-risk or metastatic breast cancer received the Theratope ${ }^{\circledR}$ STn-KLH vaccine (Biomira Inc., Edmonton, Alberta, Canada) following high-dose chemotherapy and stem cell rescue. Out of 26 evaluable patients, the authors described a positive enzyme-linked immunospot assay for IFN- $\gamma$ in 11 patients. The vaccine was well tolerated. Patients with highly specific lytic activity of peripheral blood lymphocytes had a longer remission compared to patients who displayed less specific immune activity $[35,36]$. In a large phase III trial, 1,028 patients with metastatic breast cancer and no evidence of progressive disease after a first-line chemotherapy, were randomized to Theratope or control during concomitant endocrine therapy. Patients with evidence of immune response had a survival benefit; patients included in the Theratope arm had an improvement in progression-free survival. A randomized, double-blind, phase III trial in 1,030 women with metastatic breast cancer failed to demonstrate a significant improvement in TTP or overall survival (OS). Analysis of a pre-stratified subset of patients receiving endocrine therapy showed a difference in OS.

\section{Wilms' Tumor Gene}

The Wilms' tumor gene (WT1) was initially identified in sporadic and hereditary cases of Wilms' tumor as being either mutated or overexpressed [37]. WT1 is involved in cell growth regulation or differentiation. As a result of the alternative use of 2 promoters, alternative splicing, alternative use of translation initiation sites, and RNA editing, the WT1 gene can encode as many as 24 different isoforms. The WT1 protein is able to bind DNA by means of 4 zinc fingers but also interacts with several other proteins and can shuttle between the nucleus and cytoplasm. Some isoforms are transcriptional activators or repressors, but others can act as RNA-processing factors [38]. WT1 is expressed in normal adult tissues of 
different mammalian species. This expression is limited to particular cell types, including glomerular podocytes, ovarian granulosa, testicular Sertoli cells, mammary duct and lobule cells, and splenic parenchyma [39, 40]. CD34+ pluripotent hematopoietic stem cells produce WT1 transiently during maturation [41-43]. One rat model study reports induction of WT1 expression in the vasculature of the heart in response to local ischemia or hypoxia. This is thought to reflect the protein's role in neoangiogenesis, which is in line with the documented expression of WT1 in the vascular endothelium of tumors. WT1 protein is expressed in blood vessels but not in cardiomyocytes of normal human heart samples. However, in cases of chronic ischemic disease, WT1 protein was detected in cardiomyocytes as well. Hypoxia can also induce WT1 protein expression in renal tubular cells [44, 45]. In contrast to the restricted expression in adult tissues, WT1 is widely expressed in a number of cancers and appears to act as an oncogene as interference with WT1 function inhibits proliferation and induces apoptosis, making WT1 a target for cancer immunotherapy.

Several WT1 antigenic HLA class I restricted peptides have been identified [46]. CTLs raised in vitro against some of these epitopes could lyze WT1-expressing cancer cells in an HLA-restricted manner. WT1-specific helper epitopes are able to elicit CD4+ helper T-cell responses [47, 48]. Peptideor DNA-based WT1 immunotherapeutics have been tested in mice. These were able to induce WT1-specific CTLs, resulting in the rejection of challenges by WT1-expressing tumor cells. Of concern was whether the expression of WT1 by a subset of CD34+ marrow cells would give rise to marrow toxicity when confronted with a vaccine-induced immune response to WT1. WT1-specific CTLs, capable of inhibiting leukemia progenitor cell colony growth, did not inhibit progenitor cell colony growth from normal marrow. Also, the induced immune response did not cause any damage to other tissues expressing
WT1 at physiological levels $[49,50]$. Results of phase I/II trials mostly evaluating HLA class I-restricted peptide vaccines in patients with WT1-positive tumors describe the results obtained after treatment of approximately 116 patients with different types of cancer [51, 52]. Half of the treated patients displayed signs of clinical activity, with a few cases of drastic tumor regression. In one of the clinical trials targeting WT1, tumor regression was observed in 2 metastatic breast cancer patients who received WT1 peptide. In 1 patient, this was associated with an increase in the numbers of WT1 tetramerpositive T cells in the peripheral blood. No damage to physiologically WT1-expressing normal tissues was reported, and the treatment was well tolerated overall [53].

\section{Conclusion}

Antigens present on cancer cells are the targets for the immune system; however, many are not truly cancer-specific as they may also be found on normal tissues. Antigens that are found and studied in breast cancer include CEA, HER2, MUC-1 which is hypoglycosylated in adenocarcinomas, carbohydrate antigens (Tn, TF, STn), p53 - a tumor suppressor gene mutated in cancers, TERT, and WT1. Therapeutic efficacy and immunogenicity are the most important characteristics that have to be taken into account when selecting TAAs as immunotherapeutic targets. The choice of specific TAAs is paramount in order to translate the most promising TAAs into vaccines for cancer treatment or prevention.

\section{Disclosure Statement}

The author has no conflicts of interest to disclose.

\section{References}

1 Parmiani G, De Filippo A, Novellino L, Castelli C: Unique human tumor antigens: immunobiology and use in clinical trials. J Immunol 2007;178:1975-1979.

2 Parmiani G, Russo V, Marrari A, Cutolo G, Casati C, Pilla L, Maccalli C, Rivoltini L, Castelli C: Universal and stemness-related tumor antigens: potential use in cancer immunotherapy. Clin Cancer Res 2007;13:5675-5679.

3 Curigliano G, Locatelli M, Fumagalli L, Goldhirsch A: Immunizing against breast cancer: a new swing for an old sword. Breast 2009;18(suppl 3):S51-54.

$\checkmark 4$ Chung MA, Luo Y, O'Donnell M, Rodriguez C, Heber W, Sharma S, Chang HR: Development and preclinical evaluation of a Bacillus CalmetteGuerin-MUC1-based novel breast cancer vaccine. Cancer Res 2003;63:1280-1287.

$\checkmark 5$ Disis ML, Schiffman K, Guthrie K, Salazar LG, Knutson KL, Goodell V, dela Rosa C, Cheever MA: Effect of dose on immune response in patients vaccinated with an her-2/neu intracellular domain protein--based vaccine. J Clin Oncol 2004;22:19161925
6 Hodge JW: Carcinoembryonic antigen as a target for cancer vaccines. Cancer Immunol Immunother 1996;43:127-134.

7 Bednarek AK, Sahin A, Brenner AJ, Johnston DA, Aldaz CM: Analysis of telomerase activity levels in breast cancer: positive detection at the in situ breast carcinoma stage. Clin Cancer Res 1997;3:11-16.

8 Stauss HJ, Thomas S, Cesco-Gaspere M, Hart DP, Xue SA, Holler A, King J, Wright G, Perro M, Pospori C, et al.: WT1-specific T cell receptor gene therapy: improving TCR function in transduced T cells. Blood Cells Mol Dis 2008;40:113-116.

$\checkmark$ Cheever MA, Allison JP, Ferris AS, Finn OJ, Hastings BM, Hecht TT, Mellman I, Prindiville SA, Viner JL, Weiner LM, et al.: The prioritization of cancer antigens: a national cancer institute pilot project for the acceleration of translational research. Clin Cancer Res 2009;15:5323-5337.

10 Banchereau J, Palucka AK: Dendritic cells as therapeutic vaccines against cancer. Nat Rev Immunol 2005;5:296-306.
11 Adema GJ, de Vries IJ, Punt CJ, Figdor CG: Migration of dendritic cell based cancer vaccines: in vivo veritas? Curr Opin Immunol 2005;17:170174.

12 Knutson KL, Schiffman K, Disis ML: Immunization with a HER-2/neu helper peptide vaccine generates HER-2/neu CD8 T-cell immunity in cancer patients. J Clin Invest 2001;107:477-484.

13 Peethambaram PP, Melisko ME, Rinn KJ, Alberts SR, Provost NM, Jones LA, Sims RB, Lin LR, Frohlich MW, Park JW: A phase I trial of immunotherapy with lapuleucel-T (APC8024) in patients with refractory metastatic tumors that express HER-2/neu. Clin Cancer Res 2009;15:59375944.

14 Kohlgraf KG, Gawron AJ, Higashi M, VanLith ML, Shen X, Caffrey TC, Anderson JM, Hollingsworth MA: Tumor-specific immunity in MUC1.Tg mice induced by immunization with peptide vaccines from the cytoplasmic tail of CD227 (MUC1) Cancer Immunol Immunother 2004;53:1068-1084. 
15 Ko BK, Kawano K, Murray JL, Disis ML, Efferson CL, Kuerer HM, Peoples GE, Ioannides CG: Clinical studies of vaccines targeting breast cancer. Clin Cancer Res 2003;9:3222-3234.

-16 Ding L, Lalani EN, Reddish M, Koganty R, Wong T, Samuel J, Yacyshyn MB, Meikle A, Fung PY, Taylor-Papadimitriou J, et al.: Immunogenicity of synthetic peptides related to the core peptide sequence encoded by the human MUC1 mucin gene: effect of immunization on the growth of murine mammary adenocarcinoma cells transfected with the human MUC1 gene. Cancer Immunol Immunother 1993;36:9-17.

17 Apostolopoulos V, Xing PX, McKenzie IF: Murine immune response to cells transfected with human MUC1: immunization with cellular and synthetic antigens. Cancer Res 1994;54:5186-5193.

18 Zhang S, Graeber LA, Helling F, Ragupathi G, Adluri S, Lloyd KO, Livingston PO: Augmenting the immunogenicity of synthetic MUC1 peptide vaccines in mice. Cancer Res 1996;56:3315-3319.

19 Acres RB, Hareuveni M, Balloul JM, Kieny MP: Vaccinia virus MUC1 immunization of mice: immune response and protection against the growth of murine tumors bearing the MUC1 antigen. J Immunother Emphasis Tumor Immunol 1993;14: 136-143.

-20 Reddish M, MacLean GD, Koganty RR, KanMitchell J, Jones V, Mitchell MS, Longenecker BM: Anti-MUC1 class I restricted CTLs in metastatic breast cancer patients immunized with a synthetic MUC1 peptide. Int J Cancer 1998;76:817823.

21 Apostolopoulos V, Pietersz GA, McKenzie IF: Cell-mediated immune responses to MUC1 fusion protein coupled to mannan. Vaccine 1996;14:930938.

-22 Apostolopoulos V, Loveland BE, Pietersz GA, McKenzie IF: CTL in mice immunized with human mucin 1 are MHC-restricted. J Immunol 1995;155:5089-5094.

-23 Apostolopoulos V, Pietersz GA, Loveland BE, Sandrin MS, McKenzie IF: Oxidative/reductive conjugation of mannan to antigen selects for $\mathrm{T} 1$ or T2 immune responses. Proc Natl Acad Sci U S A 1995;92:10128-10132.

24 Gilewski T, Adluri S, Ragupathi G, Zhang S, Yao TJ, Panageas K, Moynahan M, Houghton A, Norton L, Livingston PO: Vaccination of highrisk breast cancer patients with mucin-1 (MUC1) keyhole limpet hemocyanin conjugate plus QS-21. Clin Cancer Res 2000;6:1693-1701.

25 Marshall JL, Gulley JL, Arlen PM, Beetham PK, Tsang KY, Slack R, Hodge JW, Doren S, Grosenbach DW, Hwang J, et al.: Phase I study of sequential vaccinations with fowlpox-CEA(6D) TRICOM alone and sequentially with vacciniaCEA(6D)-TRICOM, with and without granulocyte-macrophage colony-stimulating factor, in patients with carcinoembryonic antigen-expressing carcinomas. J Clin Oncol 2005;23:720-731.

26 Marshall JL, Hoyer RJ, Toomey MA, Faraguna K, Chang P, Richmond E, Pedicano JE, Gehan E, Peck RA, Arlen P, et al.: Phase I study in advanced cancer patients of a diversified prime-and-boost vaccination protocol using recombinant vaccinia virus and recombinant nonreplicating avipox virus to elicit anti-carcinoembryonic antigen immune responses. J Clin Oncol 2000;18:3964-3973.
27 Von Mehren M, Arlen P, Gulley J, Rogatko A, Cooper HS, Meropol NJ, Alpaugh RK, Davey M, McLaughlin S, Beard MT, et al.: The influence of granulocyte macrophage colony-stimulating factor and prior chemotherapy on the immunological response to a vaccine (ALVAC-CEA B7.1) in patients with metastatic carcinoma. Clin Cancer Res 2001;7:1181-1191.

28 Aarts WM, Schlom J, Hodge JW: Vector-based vaccine/cytokine combination therapy to enhance induction of immune responses to a self-antigen and antitumor activity. Cancer Res 2002;62:57705777.

29 Rosenberg SA: Cancer vaccines based on the identification of genes encoding cancer regression antigens. Immunol Today 1997;18:175-182.

30 Vonderheide RH: Telomerase as a universal tumor-associated antigen for cancer immunotherapy. Oncogene 2002;21:674-679.

31 Nair SK, Heiser A, Boczkowski D, Majumdar A, Naoe M, Lebkowski JS, Vieweg J, Gilboa E: Induction of cytotoxic $\mathrm{T}$ cell responses and tumor immunity against unrelated tumors using telomerase reverse transcriptase RNA transfected dendritic cells. Nat Med 2000;6:1011-1017.

32 Vonderheide RH, Domchek SM, Schultze JL, George DJ, Hoar KM, Chen DY, Stephans KF, Masutomi K, Loda M, Xia Z, et al.: Vaccination of cancer patients against telomerase induces functional antitumor CD8+ T lymphocytes. Clin Cancer Res 2004;10:828-839.

33 MacLean GD, Miles DW, Rubens RD, Reddish MA, Longenecker BM: Enhancing the effect of THERATOPE STn-KLH cancer vaccine in patients with metastatic breast cancer by pretreatment with low-dose intravenous cyclophosphamide. J Immunother Emphasis Tumor Immunol 1996;19:309-316.

34 Miles DW, Towlson KE, Graham R, Reddish M, Longenecker BM, Taylor-Papadimitriou J, Rubens RD: A randomised phase II study of sialylTn and DETOX-B adjuvant with or without cyclophosphamide pretreatment for the active specific immunotherapy of breast cancer. Brit J Cancer 1996;74:1292-1296.

-35 Sandmaier BM, Oparin DV, Holmberg LA, Reddish MA, MacLean GD, Longenecker BM: Evidence of a cellular immune response against sialyl-Tn in breast and ovarian cancer patients after high-dose chemotherapy, stem cell rescue, and immunization with Theratope STn-KLH cancer vaccine. J Immunother 1999;22:54-66.

36 Holmberg LA, Oparin DV, Gooley T, Lilleby $\mathrm{K}$, Bensinger W, Reddish MA, MacLean GD, Longenecker BM, Sandmaier BM: Clinical outcome of breast and ovarian cancer patients treated with high-dose chemotherapy, autologous stem cell rescue and THERATOPE STn-KLH cancer vaccine. Bone Marrow Transplant 2000;25:1233-1241.

\$37 Pelletier J, Bruening W, Li FP, Haber DA, Glaser T, Housman DE: WT1 mutations contribute to abnormal genital system development and hereditary Wilms' tumour. Nature 1991;353:431434.

38 Hohenstein P, Hastie ND: The many facets of the Wilms' tumour gene, WT1. Hum Mol Genet 2006;15:R196-201. 39 Wagner KD, Wagner N, Schley G, Theres H,
Scholz H: The Wilms' tumor suppressor Wt1 encodes a transcriptional activator of the class IV POU-domain factor Pou4f2 (Brn-3b). Gene 2003;305:217-223.
40 Algar E: A review of the Wilms' tumor 1 gene (WT1) and its role in hematopoiesis and leukemia. J Hematother Stem Cell Res 2002;11:589-599.

41 Menssen HD, Renkl HJ, Entezami M, Thiel E: Wilms' tumor gene expression in human CD34+ hematopoietic progenitors during fetal development and early clonogenic growth. Blood 1997; 89:3486-3487.

42 Maurer U, Weidmann E, Karakas T, Hoelzer D, Bergmann L: Wilms tumor gene (wt1) mRNA is equally expressed in blast cells from acute myeloid leukemia and normal CD34+ progenitors. Blood 1997;90:4230-4232.

43 Hosen N, Sonoda Y, Oji Y, Kimura T, Minamiguchi H, Tamaki H, Kawakami M, Asada M, Kanato K, Motomura M, et al.: Very low frequencies of human normal CD34+ haematopoietic progenitor cells express the Wilms' tumour gene WT1 at levels similar to those in leukaemia cells. Brit J Haematol 2002;116:409-420.

44 Wagner KD, Wagner N, Wellmann S, Schley G, Bondke A, Theres H, Scholz H: Oxygen-regulated expression of the Wilms' tumor suppressor Wt1 involves hypoxia-inducible factor-1 (HIF-1). FASEB J 2003;17:1364-1366

45 Wagner KD, Wagner N, Bondke A, Nafz B, Flemming B, Theres H, Scholz H: The Wilms tumor suppressor $\mathrm{Wt} 1$ is expressed in the coronary vasculature after myocardial infarction. FASEB J 2002;16:1117-1119.

-46 Oka Y, Tsuboi A, Kawakami M, Elisseeva OA, Nakajima H, Udaka K, Kawase I, Oji Y, Sugiyama H: Development of WT1 peptide cancer vaccine against hematopoietic malignancies and solid cancers. Curr Med Chem 2006;13:2345-2352.

47 Hernandez-Caballero E, Mayani H, Montesinos JJ, Arenas D, Salamanca F, Penaloza R: In vitro leukemic cell differentiation and WT1 gene expression. Leukemia Res 2007;31:395-397.

48 Fujiki F, Oka Y, Kawakatsu M, Tsuboi A, Nakajima H, Elisseeva OA, Harada Y, Li Z, Tatsumi N, Kamino E, et al.: A WT1 proteinderived, naturally processed 16-mer peptide, WT1(332), is a promiscuous helper peptide for induction of WT1-specific Th1-type CD4(+) T cells. Microbiol Immunol 2008;52:591-600.

49 Tsuboi A, Oka Y, Ogawa H, Elisseeva OA, Li H Kawasaki K, Aozasa K, Kishimoto T, Udaka K, Sugiyama H: Cytotoxic T-lymphocyte responses elicited to Wilms' tumor gene WT1 product by DNA vaccination. J Clin Immunol 2000;20:195-202.

50 Rosenfeld C, Cheever MA, Gaiger A: WT1 in acute leukemia, chronic myelogenous leukemia and myelodysplastic syndrome: therapeutic potential of WT1 targeted therapies. Leukemia 2003;17:1301-1312.

51 Iiyama T, Udaka K, Takeda S, Takeuchi T, Adachi YC, Ohtsuki Y, Tsuboi A, Nakatsuka S, Elisseeva OA, Oji Y, et al.: WT1 (Wilms' tumor 1) peptide immunotherapy for renal cell carcinoma. Microbiol Immunol 2007;51:519-530.

52 Keilholz U, Letsch A, Busse A, Asemissen AM, Bauer S, Blau IW, Hofmann WK, Uharek L, Thiel E, Scheibenbogen C: A clinical and immunologic phase 2 trial of Wilms tumor gene product 1 (WT1) peptide vaccination in patients with AML and MDS. Blood 2009;113:6541-6548.

53 Oka Y, Tsuboi A, Taguchi T, Osaki T, Kyo T, Nakajima H, Elisseeva OA, Oji Y, Kawakami M, Ikegame K, et al.: Induction of WT1 (Wilms' tumor gene)-specific cytotoxic T lymphocytes by WT1 peptide vaccine and the resultant cancer regression. Proc Natl Acad Sci U S A 2004;101:1388513890. 